\title{
MicroRNA-150 functions as an antioncogenic regulator in osteosarcoma
}

\author{
JIN XU ${ }^{1,2^{*}}$, ZENGLIANG WANG $^{2^{*}}$, ZHICHAO LIAO $^{3}$, DONG DAI $^{3}$ and XINLONG MA ${ }^{1,2}$ \\ ${ }^{1}$ Department of Orthopaedic Surgery, Tianjin Medical University, Tianjin 300070; \\ ${ }^{2}$ Department of Orthopaedic Surgery, Tianjin Hospital, Tianjin 300211 ; ${ }^{3}$ Department of Orthopaedic Surgery, \\ Tianjin Medical University Cancer Institute and Hospital, Tianjin 300060, P.R. China
}

Received September 18, 2015; Accepted February 13, 2017

DOI: $10.3892 / \mathrm{ol} .2017 .6393$

\begin{abstract}
Numerous studies have demonstrated that microRNAs (miRs) are involved in several physiological and pathological processes, and participate in cancer initiation and progression. The abnormal expression of miR-150 has been reported in numerous types of human cancer. However, at present there are no studies of miR-150 in osteosarcoma (OS). Reverse transcription-quantitative polymerase chain reaction was performed to measure miR-150 expression levels in OS tissues and cell lines. Subsequent to transfection with miR-150 mimics or zinc finger E-box binding homeobox 1 (ZEB1) small interfering RNA, an MTT assay, Transwell migration and invasion assays, western blotting and a Dual-Luciferase reporter assay were performed in human OS cell lines. The present study revealed that miR-150 was downregulated in OS tissues and cell lines. In addition, the expression levels of miR-150 were correlated with the clinical stage and degree of distant metastasis of patients with OS. In addition, ZEB1 was identified as a direct target of miR-150 in vitro. In conclusion, miR-150 targeted ZEB1 to function as an antioncogenic regulator in OS. These findings elucidated a novel underlying mechanism for the pathogenic process in OS carcinogenesis and progression, and may provide novel targeted therapeutic regimens for patients with OS.
\end{abstract}

\section{Introduction}

Osteosarcoma (OS) is the most common type of primary malignancy of the bones and joints, and accounts for $2.4 \%$ of all malignancies in child and adolescent patients, and $\sim 20 \%$ of all types of primary bone cancer $(1,2)$. The estimated

Correspondence to: Professor Xinlong Ma, Department of Orthopaedic Surgery, Tianjin Hospital, 406 Jiefangnan Road, Tianjin 300211, P.R. China

E-mail: xinlongma406@163.com

${ }^{*}$ Contributed equally

Key words: microRNA-150, osteosarcoma, ZEB1, growth, metastasis incidence of OS is four to five cases per million worldwide, with a peak incidence at 15-19 years old (3). Currently, the main standard therapeutic methods for OS include local control of the primary lesion by surgery and the use of combinational chemotherapy (4). OS cells are characteristically aggressive, with capabilities of rapid growth and early metastasis. Lymph node and/or distant metastasis is developed in $>30 \%$ of patients with locally advanced OS $(5,6)$. Although progress in therapeutic treatments has occurred, prognosis remains poor. The 5-year overall survival rate for locally advanced patients is $60-70 \%$, whereas for patients who present with metastatic disease it is $<30 \%(7,8)$. Understanding the molecular mechanisms underlying the rapid growth and early metastasis of OS and investigating novel therapeutic regimens to prevent metastasis during the early stages is, therefore, important.

microRNAs (miRNAs/miRs) are a group of endogenous, non-protein-coding and short RNAs (18-25 nucleotides) with highly conserved sequences in plants, animals and DNA viruses (9). Several studies have demonstrated that miRNAs regulate mRNA expression in tumor and normal cells, by binding to sites in the 3' untranslated regions (3'UTR) of mRNAs in a base-pairing manner, resulting in the degradation of mRNAs or translational inhibition at the post-transcription level (10-12). It has been estimated that miRNAs regulate more than two-thirds of human genes (13). Abnormal expression of miRNAs has been reported in various diseases, particularly in cancer (14). Numerous studies have suggested that the abnormal expression of miRNAs in cancer serves a crucial function in several physiological and pathological processes, including cell growth, differentiation, the cell cycle, apoptosis, survival, migration and invasion $(15,16)$. miRNAs may act as tumor suppressors or oncogenes in the initiation and development of various types of human malignancies, depending on the roles of the target mRNAs (17). Therefore, an investigation into miRNAs may reveal the prognostic value and therapeutic potential of miRNAs in OS.

The present study aimed to investigate the expression, functions and molecular mechanisms of miR-150 in OS carcinogenesis and progression. In the present study, the miR-150 expression levels in OS tissues and cell lines were analyzed, followed by functional studies of miR-150 in human OS cell lines. The results of the present study revealed that miR-150 was significantly downregulated in OS tissues and 
cell lines. Low expression levels of miR-150 were associated with clinical stage and distant metastasis in patients with OS. In addition, miR-150 inhibited OS cell growth, migration and invasion. Additionally, zinc finger E-box binding homeobox 1 (ZEB1) was identified as a direct target of miR-150. Therefore, miR-150 was determined to be an antioncogenic regulator in OS via the direct targeting of ZEB1. These findings indicated a novel molecular mechanism underlying the pathogenic process in OS carcinogenesis and progression, and may facilitate the development of novel targeted therapeutic regimens for patients with OS.

\section{Materials and methods}

Clinical specimens. The current study was approved by the Ethical Review Committee of Tianjin Hospital (Tianjin, China). In addition, written informed consent and clinicopathological information was obtained from each patient with OS involved in the present study. A total of 67 pairs of OS tissues and matched normal adjacent tissues (NATs) were obtained from patients (39 male and 28 female; age range, 16-65 years) who underwent surgical resection at Tianjin Hospital between June 2013 and January 2015. All the patients with OS had not received any therapeutic treatments prior to surgery. Specimens had been histologically and clinically diagnosed following surgery. Tissues were snap-frozen in liquid nitrogen and stored at $-80^{\circ} \mathrm{C}$ until use.

Cell culture. The HOS, U2OS, MG-63 and SAOS-2 human OS cell lines and the human normal osteoblastic hFOB 1.19 cell line were purchased from the American Type Culture Collection (Manassas, VA, USA). The HEK293T cell line was obtained from the Chinese Center for Type Culture Collection (Wuhan, China). All cell lines were maintained in Dulbecco's modified Eagle's medium (DMEM; Gibco; Thermo Fisher Scientific, Inc., Waltham, MA, USA) containing $10 \%$ fetal bovine serum (FBS; Gibco; Thermo Fisher, Scientific, Inc.), $100 \mathrm{U} / \mathrm{ml}$ penicillin and $100 \mathrm{U} / \mathrm{ml}$ streptomycin (Gibco; Thermo Fisher Scientific, Inc.). All cell lines were cultured at $37^{\circ} \mathrm{C}$ in a humidified atmosphere containing $5 \% \mathrm{CO}_{2}$.

Cell transfection. miR-150 mimics and negative controls (NC) were obtained from GenePharma Co., Ltd. (Shanghai, China). ZEB1 small interfering RNA (siRNA) and negative control (NC) siRNA were purchased from Guangzhou RiboBio (Guangzhou, China). When the growth of the cells reached the exponential phase they were plated into 6-well plates at a density of $7.5 \times 10^{5}$ per well and maintained in DMEM containing 10\% FBS without antibiotics. The cells were transfected with miR-150 mimics, NC, ZEB1 siRNA or NC siRNA using Lipofectamine ${ }^{\circledR} 2000$ (Invitrogen; Thermo Fisher Scientific, Inc.), according to the manufacturer's protocol.

Reverse transcription-quantitative polymerase chain reaction (RT-qPCR). Total RNA was extracted from tissues and cells using TRIzol ${ }^{\circledR}$ reagent (Invitrogen; Thermo Fisher Scientific, Inc.) according to the manufacturer's protocol. cDNA was synthesized using a PrimeScript RT Reagent kit
(Takara Bio, Inc., Otsu, Japan). RT-qPCR was carried out to evaluate miR-150 expression with a SYBR Premix Ex Taq ${ }^{\mathrm{TM}}$ kit (Takara Biotechnology Co., Ltd., Dalian, China), and U6 small nuclear RNA was used as an internal control. The thermocycling conditions for qPCR of miR-150 and U6 were as follows: $95^{\circ} \mathrm{C}$ for $30 \mathrm{sec}$; 40 cycles of $95^{\circ} \mathrm{C}$ for $5 \mathrm{sec} ; 60^{\circ} \mathrm{C}$ for $30 \mathrm{sec}$. ZEB1 mRNA expression was analyzed using SYBR Green PCR Master Mix (Applied Biosystems; Thermo Fisher Scientific, Inc.), and GADPH was used as the internal reference gene. The thermocycling conditions for qPCR of ZEB1 and GADPH were as follows: $95^{\circ} \mathrm{C}$ for $10 \mathrm{~min}$; 40 cycles of $95^{\circ} \mathrm{C}$ for $15 \mathrm{sec}$; $60^{\circ} \mathrm{C}$ for $1 \mathrm{~min}$. RT-qPCR was performed on an Applied Biosystems 7500 Real-time PCR detection system (ABI; Thermo Fisher Scientific, Inc.). Relative expression was calculated using the $2^{-\Delta \Delta \mathrm{Cq}}$ method (18).

MTT assay. An MTT assay (Sigma-Aldrich; Merck KGaA, Darmstadt, Germany) was performed to assess the OS cell viability. After $24 \mathrm{~h}$ of transfection at $37^{\circ} \mathrm{C}$, the cells were collected and seeded into 96 -well plates at a density of 3,000 cells/well. Cells were cultured in a cell culture box at $37^{\circ} \mathrm{C}$ with $5 \% \mathrm{CO}_{2}$ for $1,2,3$ and 4 days. A total of $20 \mu 1 \mathrm{MTT}$ solution $(5 \mathrm{mg} / \mathrm{ml})$ was added into each well and incubated for a further $4 \mathrm{~h}$ at $37^{\circ} \mathrm{C}$. Then, the cells were lysed in $150 \mu \mathrm{l}$ dimethyl sulfoxide for $10 \mathrm{~min}$ at $37^{\circ} \mathrm{C}$. The absorbance was measured using a microplate reader (Bio-Rad Laboratories, Inc., Hercules, CA, USA) at a $490 \mathrm{~nm}$ wavelength. Each sample was evaluated in triplicate.

Transwell migration and invasion assays. Cell migration and invasion assays were used to evaluate OS cell motility ability using Transwell chambers ( $8 \mu \mathrm{m}$ pore size; Costar, Cambridge, MA, USA). For the cell invasion assay, the Transwell chamber was coated with $50 \mu \mathrm{g}$ Matrigel (BD Biosciences, San Jose, CA, USA), according to the manufacturer's protocol. After $48 \mathrm{~h}$ of transfection, cells were collected, $1 \times 10^{5}$ cells were resuspended in $200 \mu \mathrm{l}$ DMEM without FBS and were then added into the upper chamber, while the lower chamber was filled with $500 \mu$ l DMEM supplemented with $20 \%$ FBS. After $24 \mathrm{~h}$ of incubation, the cells were fixed with $100 \%$ methanol for $10 \mathrm{~min}$ and stained with $0.5 \%$ crystal violet for $20 \mathrm{~min}$. Subsequently, cells that had not migrated or invaded to the lower membrane were carefully removed with cotton swabs. The cells in $>5$ randomly selected fields (magnification, $\mathrm{x} 100$ ) were counted under an inverted microscope (CKX41; Olympus Corporation, Tokyo, Japan). All experiments were repeated at least three times.

miR-150 targets prediction. The target genes of miR-150 were predicted using the following TargetScan (http://www .targetscan.org/index. html), PicTar (http://pictar.mdc-berlin .de/) and miRanda (http://www.microrna.org).

Western blot. After a 72-h transfection, proteins were harvested from cells using RIPA lysis buffer (Beyotime Institute of Biotechnology, Haimen, China). The protein concentration was quantified using a bicinchoninic acid protein assay kit (Pierce; Thermo Fisher Scientific, Inc.). Equal amount of proteins $(20 \mu \mathrm{g})$ were subjected to $10 \%$ SDS-PAGE and electrotransferred to polyvinylidene 

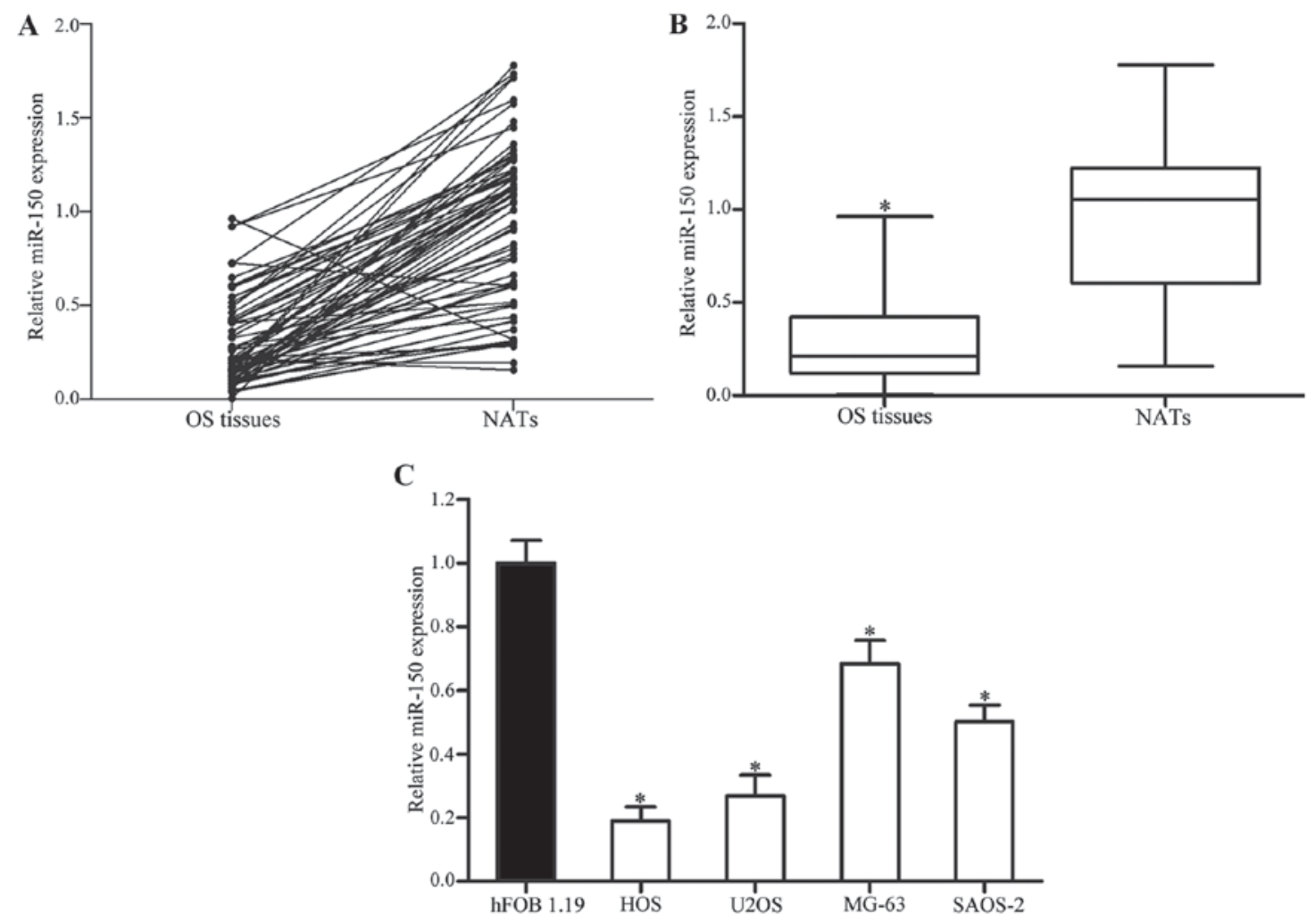

Figure 1. miR-150 expression in OS tissues and cell lines. (A and B) miR-150 was significantly downregulated in OS tissues compared with in NATs. (C) Expression levels of miR-150 decreased in HOS, U2OS, MG-63 and SAOS-2 cell lines compared with in hFOB 1.19 cells. "P<0.05, compared with the respective controls. miR, microRNA; OS, osteosarcoma; NATs, normal adjacent tissues.

fluoride membranes (EMD Millipore, Billerica, MA, USA). The membranes were blocked with $5 \%$ non-fat milk in Tris-buffered saline (TBS) at room temperature for $2 \mathrm{~h}$. Then, the membranes were incubated with primary antibodies, including a mouse anti-human monoclonal ZEB1 antibody (1:1,000 dilution; cat. no. sc-81428; Santa Cruz Biotechnology, Inc., Dallas, TX, USA) and an anti-human monoclonal GADPH antibody (1:1,000 dilution; cat. no. sc-59540; Santa Cruz Biotechnology, Inc.), overnight at $4^{\circ} \mathrm{C}$. Subsequent to washing with TBS/Tween-20 three times, the membranes were incubated with corresponding horseradish peroxidase-conjugated secondary antibodies (1:3,000 dilution; cat. no. A0192; Beyotime Institute of Biotechnology) at room temperature for $1 \mathrm{~h}$. The protein blots were visualized with enhanced chemiluminescence (Pierce; Thermo Fisher Scientific, Inc.). GADPH was used as a loading control.

Dual-Luciferase reporter assay. PGL3-ZEB1-3'UTR wild type (Wt) and PGL3-ZEB1-3'UTR mutant (Mut) was obtained from GenePharma Co., Ltd. HEK293T cells were seeded into 12-well plates and transfected with miR-150 mimics or NC, and PGL3-ZEB1-3'UTR Wt or PGL3-ZEB1-3'UTR Mut using Lipofectamine ${ }^{\circledR} 2000$. After 48 h of transfection, firefly and Renilla luciferase activities were measured using a Dual-Luciferase Reporter Assay system (Promega Corporation, Madison, WI, USA), according to the manufacturer's protocol. Firefly luciferase activities were normalized to Renilla luciferase activities for each well.
Statistical analysis. The data are presented as the mean \pm standard deviation, and were compared with Student's t-tests or one-way analysis of variance and multiple comparisons using the SPSS version 16.0 statistical software package (SPSS, Inc., Chicago, IL, USA). SNK was utilized to compare the two groups in multiple groups studies. $\mathrm{P}<0.05$ was considered to indicate a statistically significant difference.

\section{Results}

miR-150 expression is decreased in OS tissues and cell lines. RT-qPCR was performed in order to evaluate miR-150 expression in OS tissues, NATs, OS cell lines and the human hFOB 1.19 normal osteoblastic cell line. As presented in Fig. 1A and B, miR-150 expression levels in OS tissues were significantly lower compared with in NATs $(\mathrm{P}<0.05)$. miR-150 was also downregulated in HOS, U2OS, MG-63 and SAOS-2 cell lines, as compared with in hFOB 1.19 cells $(\mathrm{P}<0.05$; Fig. 1C). These results suggested that miR-150 may serve an important role in OS.

Correlation between miR-150 expression and clinicopathological features in patients with OS. In the present study, an investigation was performed into whether the expression levels of miR-150 were associated with clinicopathological features in patients with OS. As presented in Table I, statistical analysis revealed that miR-150 expression was significantly associated with the clinical stage $(\mathrm{P}=0.016)$ and distant metastasis $(\mathrm{P}=0.027)$ in patients with OS. However, 
Table I. Correlation between expression of miR-150 and clinicopathological features in patients with osteosarcoma.

\begin{tabular}{|c|c|c|c|c|}
\hline \multirow[b]{2}{*}{$\begin{array}{l}\text { Clinical } \\
\text { features }\end{array}$} & \multirow[b]{2}{*}{$\begin{array}{c}\text { Patient } \\
\text { no. }\end{array}$} & \multicolumn{2}{|c|}{$\begin{array}{l}\text { miR-150 } \\
\text { expression }\end{array}$} & \multirow[b]{2}{*}{ P-value } \\
\hline & & $\begin{array}{c}\text { Low } \\
(\mathrm{n}=38)\end{array}$ & $\begin{array}{l}\text { High } \\
(\mathrm{n}=29)\end{array}$ & \\
\hline Sex & & & & 0.803 \\
\hline Male & 39 & 23 & 16 & \\
\hline Female & 28 & 15 & 13 & \\
\hline Age & & & & 0.204 \\
\hline$<50$ years & 40 & 26 & 14 & \\
\hline$\geq 50$ years & 27 & 12 & 15 & \\
\hline Anatomical location & & & & 1.000 \\
\hline Tibia/femur & 39 & 22 & 17 & \\
\hline Elsewhere & 28 & 16 & 12 & \\
\hline Tumor size (cm) & & & & 0.624 \\
\hline$<8 \mathrm{~cm}$ & 33 & 20 & 13 & \\
\hline$\geq 8 \mathrm{~cm}$ & 34 & 18 & 16 & \\
\hline Clinical stage & & & & $0.016^{\mathrm{a}}$ \\
\hline I-II & 35 & 15 & 20 & \\
\hline III & 32 & 23 & 9 & \\
\hline Distant metastasis & & & & $0.027^{\mathrm{a}}$ \\
\hline Present & 34 & 24 & 10 & \\
\hline Absent & 33 & 14 & 19 & \\
\hline
\end{tabular}

${ }^{\mathrm{a}} \mathrm{P}<0.05$, vs. control; miR, microRNA.

no correlation was observed between miR-150 expression and other clinicopathological factors, including sex, age, anatomical location and tumor size.

miR-150 inhibits the proliferation of OS cells. To investigate the functional roles of miR-150 in OS, the present study transfected miR-150 mimics into human OS cells. miR-150 expression levels in HOS and U2OS cells were low, as compared with in the other cell lines investigated. Thus, HOS and U2OS cells were selected for transfection with miR-150 mimics or the NC. Subsequent to a transfection of $48 \mathrm{~h}$, miR-150 expression was quantified by RT-qPCR. As presented in Fig. 2A, miR-150 expression level was markedly elevated by miR-150 mimics in HOS and U2OS cells $(\mathrm{P}<0.05)$.

MTT assays were used to measure OS cell proliferation subsequent to transfection with miR-150 mimics or NC. As depicted in Fig. 2B, miR-150 inhibited the growth of HOS and U2OS cells. After $96 \mathrm{~h}$ of transfection, the rate at which miR-150 suppresses cell proliferation reached $26.05 \pm 4.24 \%$ in HOS cells and $30.87 \pm 5.57 \%$ in U2OS cells. These results indicated that miR-150 may function as a novel tumor suppressor in OS.

miR-150 inhibits the migration and invasion abilities of $O S$ cells. To evaluate the functions of miR-150 in OS metastasis, migration and invasion assays were performed using Transwell chambers. As presented in Fig. 3, miR-150 inhibited HOS and U2OS cell migratory and invasive abilities $(\mathrm{P}<0.05)$. These findings suggest that miR-150 may serve a critical role in OS metastasis.

ZEB1 is a direct target of $m i R-150$ in vitro. TargetScan, PicTar and miRanda were used to explore the molecular mechanism of miR-150 in OS. ZEB1 was identified as a target of miR-150 in all three prediction programs (Fig. 4A). RT-qPCR and western blotting were then performed to measure ZEB1 expression at the mRNA and protein levels subsequent to transfection with miR-150 mimics. As indicated in Fig. 4B, ZEB1 was significantly downregulated at the mRNA level in HOS and U2OS cells subsequent to transfection with miR-150 mimics $(\mathrm{P}<0.05)$. Similarly, western blotting revealed that ZEB1 protein expression was downregulated in miR-150 mimic-transfected HOS and U2OS cells ( $\mathrm{P}<0.05$; Fig. 4C).

Finally, Dual-Luciferase reporter assays were performed to explore whether miR-150 directly targets the 3'UTR of ZEB1. As presented in Fig. 4D, miR-150 significantly inhibited PGL3-ZEB1-3'UTR Wt luciferase activity, but not the PGL3-ZEB1-3'UTR Mut luciferase activity, in HEK293T cells $(P<0.05)$. These results demonstrate that $Z E B 1$ is a direct target gene of miR-150 in vitro.

ZEB1 is involved in miR-150-mediated tumor suppression functions in OS cells. To determine whether ZEB1 serves as a critical mediator of the suppressive functions of miR-150 on OS cell proliferation, migration and invasion, the present study transfected ZEB1 siRNA or NC siRNA into HOS and U2OS cells. After $72 \mathrm{~h}$ of transfection, western blot analysis was performed to determine ZEB1 protein expression. As indicated in Fig. 5A, ZEB1 was significantly downregulated in miR-150 mimic-transfected HOS and $\mathrm{U} 2 \mathrm{OS}$ cells $(\mathrm{P}<0.05)$.

In the MTT assay, the knockdown of ZEB1 decreased HOS and $\mathrm{U} 2 \mathrm{OS}$ cell proliferation $(\mathrm{P}<0.05$; Fig. $5 \mathrm{~B})$. In addition, in migration and invasion assays, silencing of ZEB1 inhibited HOS and U2OS cell migratory and invasive abilities $(\mathrm{P}<0.05$; Fig. 5C). These results demonstrated that the functions of ZEB1 siRNA were similar to those induced by miR-150 in HOS and U2OS cells, suggesting ZEB1 may be a functional target of miR-150 in OS.

\section{Discussion}

Since their discovery, miRNAs have received considerable attention (19). Several studies have indicated that miRNAs contribute to various physiological and pathological processes, and participate in the initiation and progression of cancer $(20,21)$. Numerous studies have demonstrated that miR-150 is downregulated in certain types of human cancer, including pancreatic cancer (22), esophageal squamous cell carcinoma (23), colorectal cancer (24), hepatocellular carcinoma (25), ovarian cancer (26) and malignant lymphoma (27). However, miR-150 was also reported to be upregulated in prostate (28), non-small cell lung (29), breast (30) and gastric cancer (31). These conflicting studies suggest that miR-150 expression levels in cancer exhibit tissue specificity. 

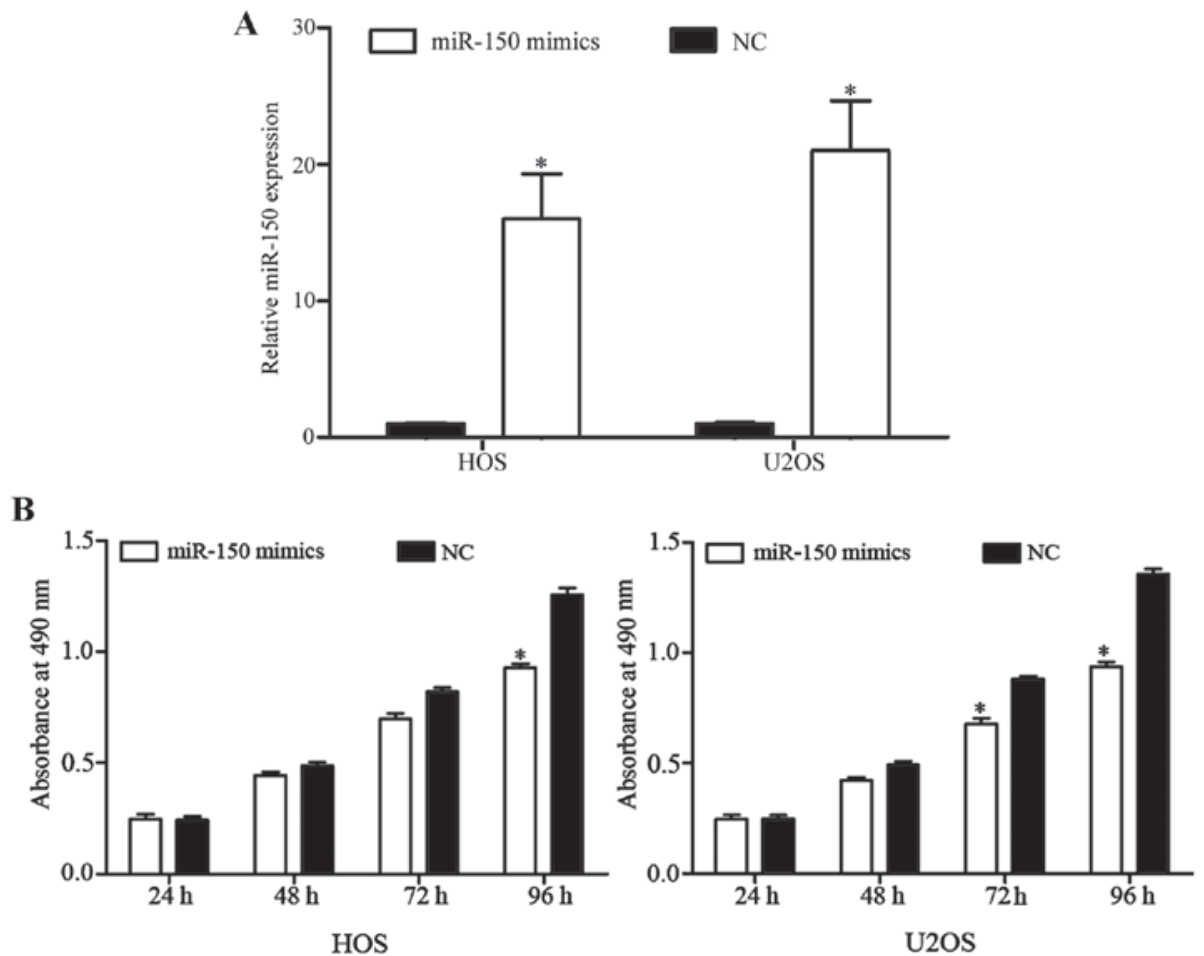

Figure 2. Upregulation of miR-150 inhibited OS cell proliferation. (A) miR-150 was significantly upregulated in miR-150 mimic-transfected HOS and U2OS cells, compared with in cells transfected with the NC. (B) MTT assays revealed that miR-150 suppressed growth in HOS and U2OS cells. " $\mathrm{P}<0.05$, compared with the respective controls. miR, microRNA; OS, osteosarcoma; NC, negative control.
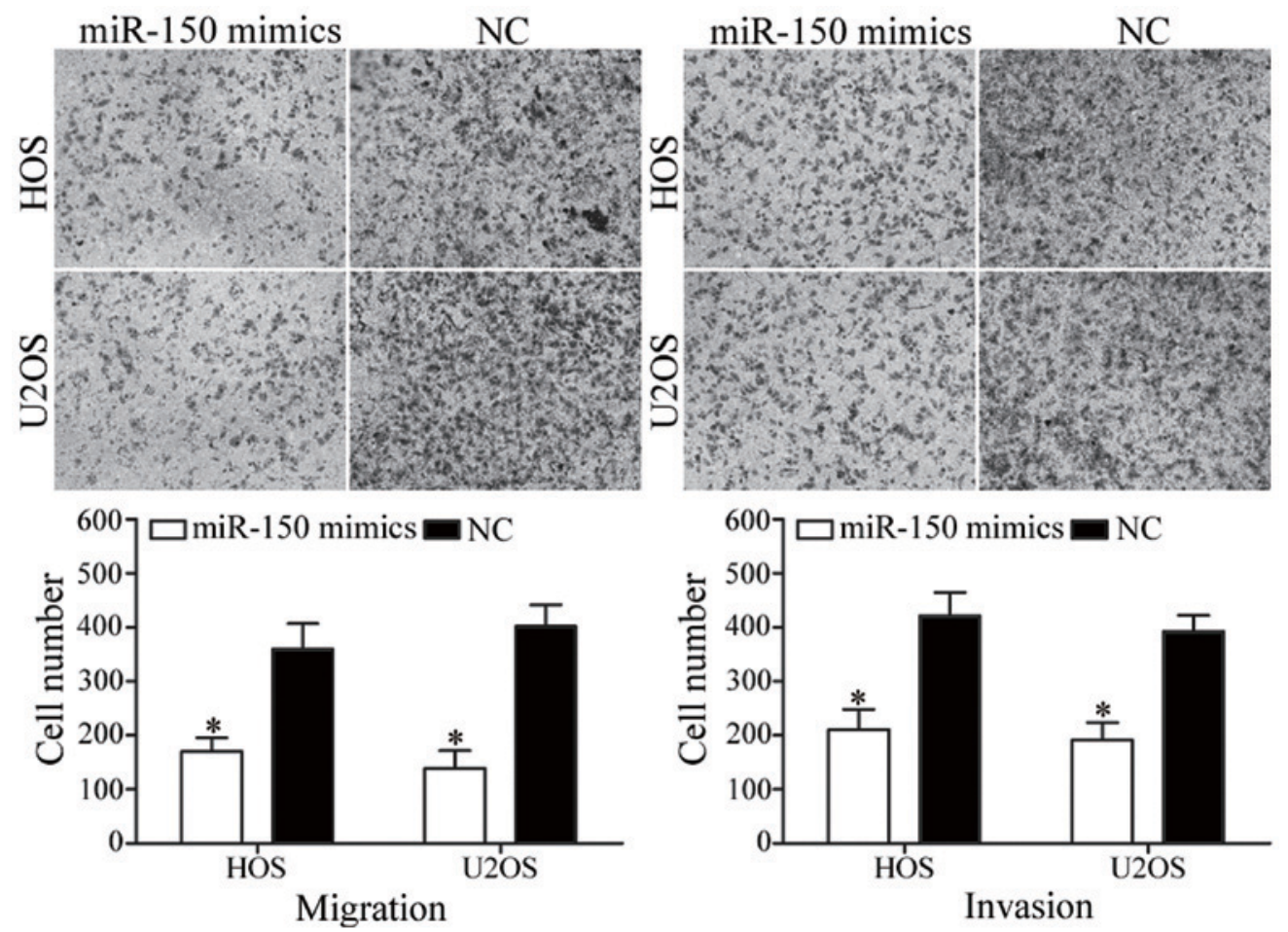

Figure 3. Cell migration and invasion was evaluated using Transwell chambers. miR-150 was revealed to suppress HOS and U2OS cell migration and invasion abilities. " $\mathrm{P}<0.05$, compared with the respective controls. miR, microRNA; NC, negative control.

In the present study, miR-195 was revealed to be significantly downregulated in OS tissues and cell lines. In addition, a low expression level of miR-150 was significantly associated with clinical stage and distant metastasis. These results suggest that miR-150 may exhibit tumor-suppressive roles in OS carcinogenesis and development.

The collective results from numerous previous functional studies demonstrated that miR-150 may be a tumor 
A

B

\begin{tabular}{|c|c|c|}
\hline ZEB1-3' UTR Wt & 5 , & AAGCUGUACAA---UUGGGAGA... \\
\hline hsa-miR-150 & 3 ' & GUGACCAUGUUCCCAACCCUCU \\
\hline EB1-3' UTR Mut & 5 , & AAGCUGUACAA-.. \\
\hline
\end{tabular}

C
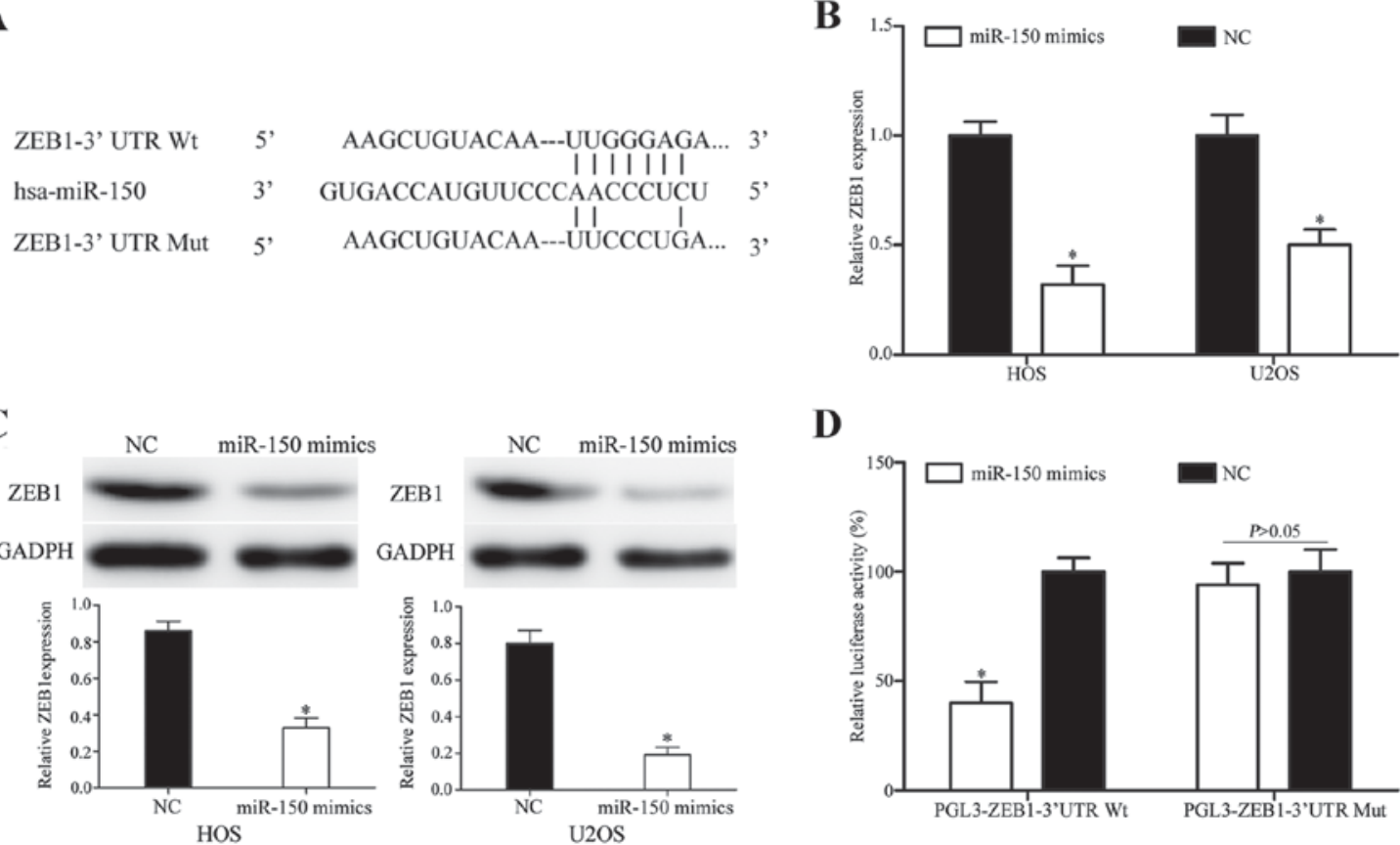

D

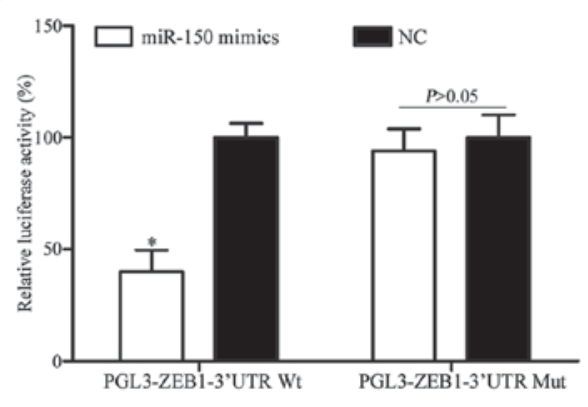

Figure 4. ZEB1 was a direct target gene of miR-150. (A) miR-150 binding site in the 3'-UTR of ZEB1 and the ZEB1 3'-UTR mutant sequence. (B) Reverse transcription-quantitative polymerase chain reaction revealed that ZEB1 was downregulated at the mRNA level in HOS and U2OS cells subsequent to transfection with miR-150 mimics. (C) Western blotting demonstrated that ZEB1 protein expression was decreased in miR-150 mimic-transfected HOS and U2OS cells. (D) miR-150 inhibited the PGL3-ZEB1-3'UTR wild type luciferase activity, but not the PGL3- ZEB1-3'UTR mutant luciferase activity in HEK293T cells. 'P<0.05, compared with the respective controls. ZEB1, zinc finger E-box binding homeobox 1; miR, microRNA; 3'-UTR, 3' untranslated region; NC, negative control; Mut, mutated; Wt, wild-type.

suppressor. For example, in pancreatic cancer, patients whose tumors were associated with low miR-150 expression exhibited higher mortality rates, compared with patients whose tumors exhibited high miR-150 expression. In addition, the upregulation of miR-150 decreased pancreatic cancer cell proliferation, migration, invasion, clonogenicity and cell cycle progression, and promoted apoptosis via the blockade of c-Myb and mucin 4, cell surface associated (32). In colorectal cancer, a low miR-150 expression group exhibited shorter survival rate and worse response to adjuvant chemotherapy compared with a high miR-150 expression group (33). miR-150 inhibited colorectal cancer cell growth and induced cell apoptosis by directly targeting c-Myb (34). Yokobori et al (23) revealed that low expression levels of miR-150 in esophageal squamous cell carcinoma were significantly associated with tumor depth, lymph node metastasis, lymphatic invasion, venous invasion, clinical staging and poor prognosis. In the aforementioned study, the upregulation of miR-150 inhibited esophageal squamous cell carcinoma cell proliferation and tumorigenicity in vivo. Therefore, upregulating miR-150 or providing analogous pharmaceutical compounds exogenously, may be an effective therapy for tumors resulting from the activation or overexpression of these oncogenes.

The functions of miRNAs are tissue-type dependent. miR-150 has been verified as an oncogene in a number of different types of cancer $(28,29,35)$. For example, in prostate cancer, miR-150 was markedly upregulated, and the high expression of miR-150 was positively associated with tumor recurrence and metastasis in prostate cancer (28). In addition, patients with prostate cancer and high miR-150 expression exhibited significantly poorer overall survival and disease-free survival compared with those patients with low miR-150 expression (28). The 5-year overall survival rate was 55.93\% in patients with prostate cancer with low miR-150 expression, whereas it was $35.19 \%$ in patients with high miR-150 expression (28). In non-small cell lung cancer, a high expression level of miR-150 was correlated with lymph node metastasis, distant metastasis and clinical tumor node metastasis stage. The 5-year overall survival rate was $69.2 \%$ in the low miR-150 expression group; however, in the high miR-150 expression group, it was $40.8 \%$ (36). In addition, the downregulation of miR-150 enhanced non-small cell lung cancer proliferation and migration, and inhibited cell apoptosis through targeting B-cell lymphoma 2 antagonist/killer 1, SRC kinase signaling inhibitor 1 and tumor protein $53(29,36,37)$. Huang et al (30) revealed that the ectopic expression of miR-150 induced breast cancer cell proliferation and clonogenicity, and suppressed cell apoptosis by directly targeting PX27. These findings also suggested that miR-150 may have important functions in these types of cancer, and may be investigated as a potential therapeutic gene for the treatment of these cancer types.

In the present study, miR-150 was revealed to inhibit OS cell proliferation, migration and invasion in vitro. Identification of miR-150 target mRNAs is important for understanding the functions of miR-150 in OS carcinogenesis and progression, and to investigate novel targeted therapies for OS. The present study identified ZEB1 as a direct target gene of miR-150 in vitro. ZEB1 is a member of the zinc finger family, which is located on the short arm of human chromosome 10 (38). Wang et al (39) 

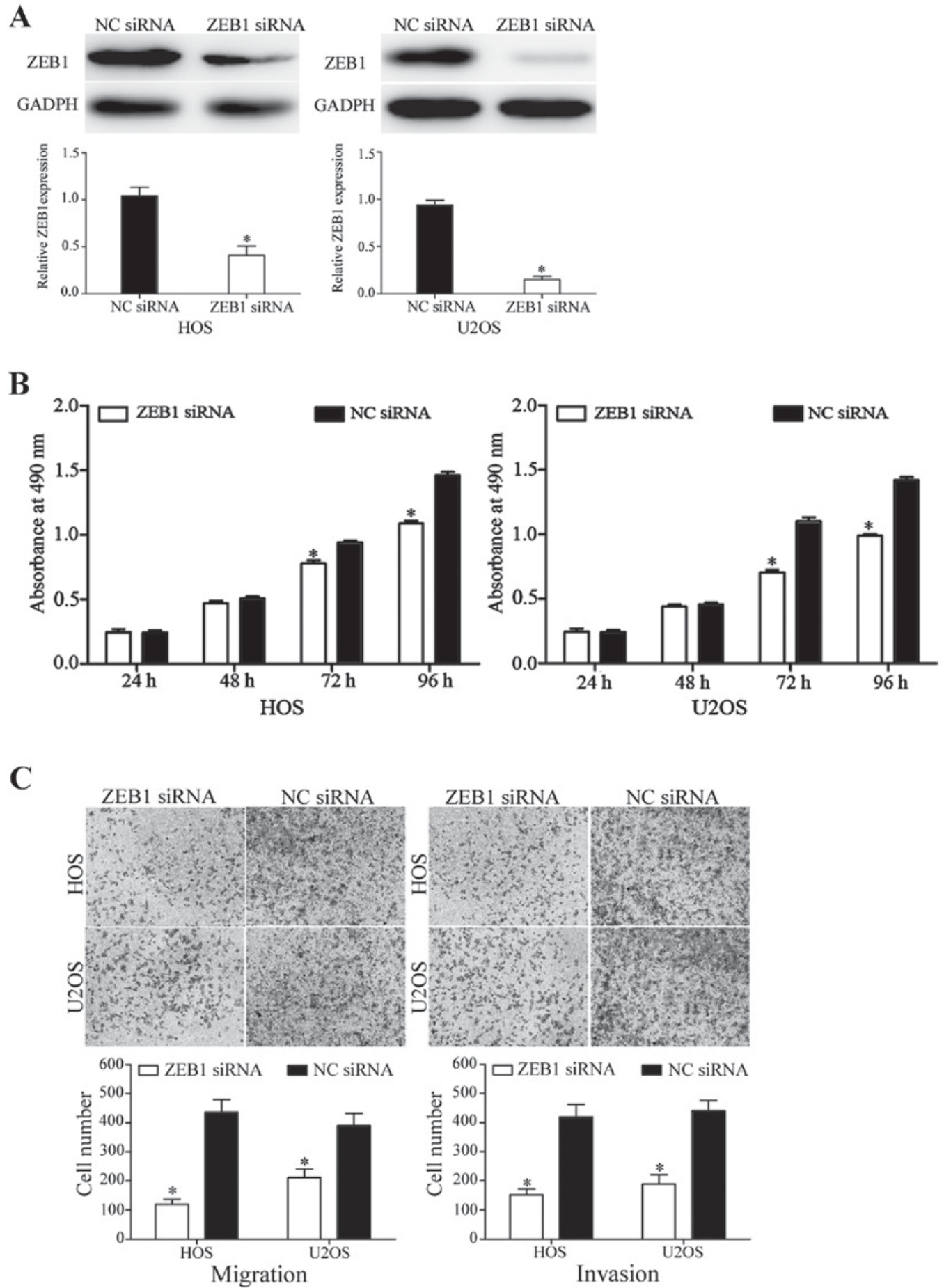

Figure 5. Effects of ZEB1 on OS cell growth, migration and invasion. (A) ZEB1 was downregulated in HOS and U2OS cells subsequent to transfection with ZEB1 siRNA. (B) ZEB1 siRNA significantly inhibited HOS and U2OS cell proliferation. (C) ZEB1 siRNA suppressed HOS and U2OS cell migration and invasion abilities. "P<0.05, compared with the respective controls. ZEB1, zinc finger E-box binding homeobox 1; OS, osteosarcoma; siRNA, small interfering RNA; NC, negative control.

verified that ZEB1 is involved in cancer progression, and that it is considered an important transcriptional regulator of E-cadherin. In OS, ZEB1 was revealed to be upregulated in patients with lung metastases compared with patients without lung metastases. In addition, the expression of ZEB1 in OS tissues was increased with increasing Enneking stage (38). These results indicated that ZEB1 may contribute to OS metastasis. Therefore, additional studies are required with respect to ZEB1 as a potential target for the inhibition of OS metastasis.
In conclusion, the present study demonstrated that miR-150 was significantly downregulated in OS tissues and cell lines. Low expression of miR-150 was associated with clinical stage and distant metastasis. In addition, miR-150 inhibited OS cell growth, migration and invasion, and ZEB1 was identified as a direct target of miR-150 in vitro. These findings suggest that miR-150 targets ZEB1 to inhibit OS growth and metastasis, a mechanism that may be investigated as a therapeutic regimen to prevent rapid growth and early metastasis in OS. 


\section{References}

1. Mirabello L, Troisi RJ and Savage SA: Osteosarcoma incidence and survival rates from 1973 to 2004: Data from the surveillance, epidemiology, and end results program. Cancer 115: 1531-1543, 2009.

2. Jin J, Cai L, Liu ZM and Zhou XS: miRNA-218 inhibits osteosarcoma cell migration and invasion by down-regulating of TIAM1, MMP2 and MMP9. Asian Pac J Cancer Prev 14: 3681-3684, 2013

3. Han K, Chen X, Bian N, Ma B, Yang T, Cai C, Fan Q, Zhou Y and Zhao TB: MicroRNA profiling identifies MiR-195 suppresses osteosarcoma cell metastasis by targeting CCND1. Oncotarget 6 : 8875-8889, 2015

4. Chou AJ, Geller DS and Gorlick R: Therapy for osteosarcoma: where do we go from here? Paediatr Drugs 10: 315-327, 2008.

5. Meyers PA, Heller G, Healey J, Huvos A, Lane J, Marcove R, Applewhite A, Vlamis V and Rosen G: Chemotherapy for nonmetastatic osteogenic sarcoma: The memorial sloan-kettering experience. J Clin Oncol 10: 5-15, 1992.

6. Lv H, Guo J, Li S and Jiang D: inhibitor reduces the proliferation and migration in osteosarcoma MG-63 cells. Exp Ther Med 8: $1575-1580,2014$

7. PosthumaDeBoer J, Witlox MA, Kaspers GJ and van Royen BJ: Molecular alterations as target for therapy in metastatic osteosarcoma: A review of literature. Clin Exp Metastasis 28: 493-503, 2011

8. Diao CY, Guo HB, Ouyang YR, Zhang HC, Liu LH, Bu J, Wang $\mathrm{ZH}$ and Xiao T: Screening for metastatic osteosarcoma biomarkers with a DNA microarray. Asian Pac J Cancer Prev 15 : 1817-1822, 2014.

9. Bentwich I, Avniel A, Karov Y, Aharonov R, Gilad S, Barad O, Barzilai A, Einat P, Einav U, Meiri E, et al: Identification of hundreds of conserved and nonconserved human microRNAs. Nat Genet 37: 766-770, 2005

10. He L and Hannon GJ: MicroRNAs: Small RNAs with a big role in gene regulation. Nat Rev Genet 5: 522-531, 2004.

11. Valencia-Sanchez MA, Liu J, Hannon GJ and Parker R: Control of translation and mRNA degradation by miRNAs and siRNAs. Genes Dev 20: 515-524, 2006.

12. Winter J, Jung S, Keller S, Gregory RI and Diederichs S: Many roads to maturity: MicroRNA biogenesis pathways and their regulation. Nat Cell Biol 11: 228-234, 2009.

13. Liu W, Zhao ZY, Shi L and Yuan WD: Tissue microRNA-126 expression level predicts outcome in human osteosarcoma. Diagn Pathol 10: 116, 2015.

14. Kong YW, Ferland-McCollough D, Jackson TJ and Bushell M: microRNAs in cancer management. Lancet Oncol 13: e249-e258, 2012.

15. Tahara H, Kay MA, Yasui W and Tahara E: MicroRNAs in Cancer: The 22nd Hiroshima Cancer Seminar/the 4th Japanese Association for RNA Interference Joint International Symposium, 30 August 2012, Grand Prince hotel Hiroshima. Jpn J Clin Oncol 43: 579-582, 2013.

16. Yates LA, Norbury CJ and Gilbert RJ: The long and short of microRNA. Cell 153: 516-519, 2013.

17. Kent OA and Mendell JT: A small piece in the cancer puzzle: MicroRNAs as tumor suppressors and oncogenes. Oncogene 25 6188-6196, 2006

18. Livak KJ and Schmittgen TD: Analysis of relative gene expression data using real-time quantitative PCR and the 2(-Delta Delta C(T)) method. Methods 25: 402-408, 2001

19. Wang $F$, Ren $X$ and Zhang X: Role of microRNA-150 in solid tumors. Oncol Lett 10: 11-16, 2015.

20. Weiland M, Gao XH, Zhou L and Mi QS: Small RNAs have a large impact: Circulating microRNAs as biomarkers for human diseases. RNA Biol 9: 850-859, 2012.

21. Ebert MS and Sharp PA: Roles for microRNAs in conferring robustness to biological processes. Cell 149: 515-524, 2012.

22. Srivastava SK, Bhardwaj A, Singh S, Arora S, Wang B, Grizzle WE and Singh AP: MicroRNA-150 directly targets MUC4 and suppresses growth and malignant behavior of pancreatic cancer cells. Carcinogenesis 32: 1832-1839, 2011.
23. Yokobori T, Suzuki S, Tanaka N, Inose T, Sohda M, Sano A, Sakai M, Nakajima M, Miyazaki T, Kato $\mathrm{H}$ and Kuwano H: MiR-150 is associated with poor prognosis in esophageal squamous cell carcinoma via targeting the EMT inducer ZEB1. Cancer Sci 104: 48-54, 2013.

24. Pizzini S, Bisognin A, Mandruzzato S, Biasiolo M, Facciolli A, Perilli L, Rossi E, Esposito G, Rugge M, Pilati P, et al: Impact of microRNAs on regulatory networks and pathways in human colorectal carcinogenesis and development of metastasis. BMC Genomics 14: 589, 2013.

25. Yu F, Lu Z, Chen B, Dong P and Zheng J: microRNA-150: A promising novel biomarker for hepatitis B virus-related hepatocellular carcinoma. Diagn Pathol 10: 129, 2015.

26. Jin M, Yang Z, Ye W, Xu H and Hua X: MicroRNA-150 predicts a favorable prognosis in patients with epithelial ovarian cancer, and inhibits cell invasion and metastasis by suppressing transcriptional repressor ZEB1. PLoS One 9: e103965, 2014.

27. Watanabe A, Tagawa H, Yamashita J, Teshima K, Nara M, Iwamoto K, Kume M, Kameoka Y, Takahashi N, Nakagawa T, et al: The role of microRNA-150 as a tumor suppressor in malignant lymphoma. Leukemia 25: 1324-1334, 2011.

28. Dezhong L, Xiaoyi Z, Xianlian L, Hongyan Z, Guohua Z, Bo S, Shenglei $\mathrm{Z}$ and Lian Z: miR-150 is a factor of survival in prostate cancer patients. J BUON 20: 173-179, 2015.

29. Gu XY, Wang J, Luo YZ, Du Q, Li RR, Shi H and Yu TP Down-regulation of miR-150 induces cell proliferation inhibition and apoptosis in non-small-cell lung cancer by targeting BAK1 in vitro. Tumour Biol 35: 5287-5293, 2014.

30. Huang S, Chen Y, Wu W, Ouyang N, Chen J, Li H, Liu X, Su F, Lin L and Yao Y: miR-150 promotes human breast cancer growth and malignant behavior by targeting the pro-apoptotic purinergic P2X7 receptor. PLoS One 8: e80707, 2013.

31. Wu Q, Jin H, Yang Z, Luo G, Lu Y, Li K, Ren G, Su T, Pan Y, Feng $\mathrm{B}$, et al: MiR-150 promotes gastric cancer proliferation by negatively regulating the pro-apoptotic gene EGR2. Biochem Biophys Res Commun 392: 340-345, 2010.

32. Yang K, He M, Cai Z, Ni C, Deng J, Ta N, Xu J and Zheng J: A decrease in miR-150 regulates the malignancy of pancreatic cancer by targeting c-Myb and MUC4. Pancreas 44: 370-379, 2015.

33. Ma Y, Zhang P, Wang F, Zhang H, Yang J, Peng J, Liu W and Qin H: miR-150 as a potential biomarker associated with prognosis and therapeutic outcome in colorectal cancer. Gut 61: $1447-1453,2012$

34. Feng J, Yang Y, Zhang P, Wang F, Ma Y, Qin H and Wang Y: miR-150 functions as a tumour suppressor in human colorectal cancer by targeting c-Myb. J Cell Mol Med 18: 2125-2134, 2014

35. Zhang N, Wei $X$ and Xu L: miR-150 promotes the proliferation of lung cancer cells by targeting P53. FEBS Lett 587: 2346-2351, 2013.

36. Yin QW, Sun XF, Yang GT, Li XB, Wu MS and Zhao J: Increased expression of microRNA-150 is associated with poor prognosis in non-small cell lung cancer. Int J Clin Exp Pathol 8: 842-846, 2015.

37. Cao M, Hou D, Liang H, Gong F, Wang Y, Yan X, Jiang X, Wang C, Zhang J, Zen K, et al: miR-150 promotes the proliferation and migration of lung cancer cells by targeting SRC kinase signalling inhibitor 1. Eur J Cancer 50: 1013-1024, 2014.

38. Shen A, Zhang Y, Yang H, Xu R and Huang G: Overexpression of ZEB1 relates to metastasis and invasion in osteosarcoma. J Surg Oncol 105: 830-834, 2012.

39. Wang Y, Yan S, Liu X, Zhang W, Li Y, Dong R, Zhang Q, Yang Q, Yuan C, Shen K and Kong B: miR-1236-3p represses the cell migration and invasion abilities by targeting ZEB1 in high-grade serous ovarian carcinoma. Oncol Rep 31: 1905-1910, 2014. 